\title{
Left ventricular function in hypothyroidism Responses to exercise and beta adrenoceptor blockade
}

\author{
J C FORFAR, A L MUIR, A D TOFT \\ From the Departments of Cardiology and Endocrinology and University Department of Medicine, Royal Infirmary, \\ Edinburgh
}

SUMMARY The effects of exercise and beta adrenoceptor blockade on left ventricular function were assessed in eight patients with hypothyroidism before and during thyroxine replacement treatment. Left ventricular ejection fraction, measured by radionuclide ventriculography, was reduced in hypothyroid patients at rest and on exercise. The rise in ejection fraction with exercise was, however, similar in both groups. Pretreatment with intravenous propranolol reduced the ejection fraction at rest $9 \%$ in both hypothyroid and euthyroid patients and reduced the rise on exercise. Directional changes in a second index of myocardial contractility based on the shape of the ventricular volume curve paralleled the changes in the ejection fraction. Left ventricular function is therefore reversibly depressed by thyroid hormone deficiency but responses to exercise and beta adrenoceptor blockade are normal. There is no evidence of altered adrenergic sensitivity in the control of myocardial contractility in hypothyroidism.

The clinical effects of varying thyroid function on the cardiovascular system have been recognised for many years. The mechanism of altered myocardial contractile function in hypothyroidism has, however, been less intensively studied. The bradycardia and cardiomegaly of myxoedema are familiar, and experimentally impaired myocardial contractility is well documented. ${ }^{1-3} \mathrm{~A}$ few studies in man, mainly using measurement of systolic time intervals, have confirmed impaired myocardial contractile function by showing prolongation of the pre-ejection period ${ }^{4-6}$ though changes in left ventricular ejection time have been inconsistent. ${ }^{467}$ More recently, echocardiographic techniques have been used to show the relation between thyroid hormone levels and velocity of circumferential fibre shortening at all levels of thyroid function. ${ }^{8}$

The influence of the sympathetic nervous system in maintaining myocardial contractile function in states of thyroid hormone deficiency is unknown. Early studies suggested that alterations in cardiac sensitivity to catecholamines could not explain the hypodynamic circulatory state characteristic of the condition. ${ }^{910}$ Radioligand binding studies, however, have shown that both beta and alpha adrenoceptor density is decreased in ventricles from propylthiouracil-treated

Accepted for publication 25 May 1982 rats, ${ }^{11}$ thus providing a mechanism for reduced adrenergic sensitivity. Myocardial cyclic AMP and contractile responses to beta adrenoceptor agonists were not assessed and therefore the functional significance of these observations remains uncertain.

The purpose of this study was to examine left ventricular contractile function and its response to exercise and beta adrenoceptor blockade in patients with hypothyroidism before and after thyroxine replacement treatment. In the absence of major changes in preload and afterload, left ventricular ejection fraction reflects the intrinsic contractile state of the heart. Radionuclide ventriculography is a sensitive and noninvasive technique for assessment of ventricular function at rest and on exercise.

\section{Patients and methods}

Eight hypothyroid patients, all women, with a mean age of 53 years (range 37 to 69 years) were investigated. The diagnosis of hypothyroidism was made clinically and on the basis of reduced levels of plasma total thyroxine $\left(T_{4}\right)$ associated with a rise in plasma thyrotrophin (TSH) (Table 1). No patients were receiving drugs at the time of the first investigation. Seven had spontaneous primary hypothyroidism and one (case 8) developed hypothyroidism after $15 \mathrm{mCi}$ radioiodine 131I for hyperthyroidism four months 
Table 1 Age at presentation, weight, and thyroid function at time of angiographic investigation in patients when hypothyroid and euthyroid

\begin{tabular}{|c|c|c|c|c|c|c|c|c|c|}
\hline \multicolumn{5}{|c|}{ Hypothyroid } & \multicolumn{5}{|c|}{ Euthyroid } \\
\hline $\begin{array}{l}\text { Case } \\
\text { No. }\end{array}$ & $\begin{array}{l}\text { Age } \\
\text { (y) }\end{array}$ & $W t(k g)$ & $\begin{array}{l}\text { Plasma total } \\
T_{4}(\text { nmolll })\end{array}$ & $\underset{(m U / l)}{\text { Plasma }} T S H$ & $W t(k g)$ & $\begin{array}{l}\text { Plasma total } \\
T_{4}(\text { nmol/l) }\end{array}$ & $\underset{(m U / l)}{\text { Plasma }} T S H$ & $\begin{array}{l}T_{4} \text { replacement } \\
\text { dose }(\mathrm{mg} / \mathrm{d})\end{array}$ & $\begin{array}{l}\text { Interval } \\
\text { between } \\
\text { Ist and 2nd } \\
\text { study (mth) }\end{array}$ \\
\hline $\begin{array}{l}1 \\
2 \\
3 \\
4 \\
5 \\
6 \\
7 \\
8\end{array}$ & $\begin{array}{l}46 \\
57 \\
59 \\
37 \\
59 \\
50 \\
69 \\
44\end{array}$ & $\begin{array}{r}55.0 \\
65.0 \\
125.0 \\
81.0 \\
69.6 \\
67.4 \\
74.5 \\
49.6\end{array}$ & $\begin{array}{r}<20 \\
35 \\
<20 \\
28 \\
26 \\
<20 \\
24 \\
<20\end{array}$ & $\begin{array}{r}>85.0 \\
51.7 \\
>85.0 \\
63.5 \\
74.0 \\
64.0 \\
>81.0 \\
36.3\end{array}$ & $\begin{array}{r}50.9 \\
61.5 \\
105.0 \\
80.0 \\
64.7 \\
64.8 \\
75.8 \\
48.6\end{array}$ & $\begin{array}{r}88 \\
116 \\
120 \\
78 \\
90 \\
79 \\
83 \\
114\end{array}$ & $\begin{array}{l}3.9 \\
3.9 \\
3.6 \\
3.8 \\
3.0 \\
2.3 \\
2.6 \\
1.7\end{array}$ & $\begin{array}{l}0.15 \\
0.15 \\
0.15 \\
0.10 \\
0.15 \\
0.10 \\
0.15 \\
0.10\end{array}$ & $\begin{array}{l}5 \\
8 \\
8 \\
5 \\
4 \\
6 \\
4 \\
5\end{array}$ \\
\hline
\end{tabular}

previously. One patient (case 2) gave a history of mild chest pain on exertion compatible with angina pectoris but specific cardiac symptoms were absent in the remainder. All gave informed consent to the investigations that were approved by our local ethical committee. All patients were clinically free from heart failure at the time of study. Cardiomegaly (cardiothoracic ratio $55 \%$ ) was noted on routine chest radiograph in case 7. Seven of the eight patients showed non-specific ST/T wave changes on the resting electrocardiogram.

Each patient was restudied between four and eight months after thyroxine replacement treatment when clinically and biochemically euthyroid. Details of thyroxine treatment and thyroid function tests when euthyroid are shown in Table 1 . Patients had been biochemically euthyroid for at least four weeks before restudy. Case 2 showed an increase in the frequency of exertional chest pain in the first six weeks after starting thyroxine and for this reason thyroxine replacement was increased gradually over six months and combined with propanolol and long acting nitrates. Both of these drugs were discontinued in this patient four weeks before repeat study without change in symptomatology.

Isotope ventriculograms were performed in the supine position with cardiac imaging in the $30^{\circ}$ left anterior oblique projection using a Nuclear Enterprises $M k$ K $\mathrm{HR}$ gamma camera. After an intravenous bolus injection of $15 \mathrm{mCi}{ }^{99 m}$ technetium electrolytically labelled human serum albumin, ${ }^{12}$ precordial counts were transferred and stored in $20 \mathrm{~ms}$ frame format in a PDP 11/34 computer (Digital Equipment Corporation). The accumulation was triggered by the $R$ wave of the patient's electrocardiogram, recorded from chest lead V5, each frame being updated by successive cardiac cycles until 300 to 500 beats had been accumulated. At the end of the accumulation period, the frames were displayed in rapid sequence or movie format on a screen. The ventricular outline was selected from the display using a joy-stick and data from within this outline displayed to produce the uncorrected ventricular volume curve. The ventricular region displayed could be checked and where necessary altered by displaying the volume curves from individual pixels. Background subtraction was made from a crescentic shell of the lateral and inferior ventricular border corrected to provide an area equal to the left ventricle and the left ventricular ejection fraction was calculated from this corrected time activity curve. ${ }^{13} \mathrm{~A}$ further index of ventricular function was calculated as the mean ejection time, (Ts) expressed as a proportion of ventricular ejection time. Ts was defined by

$$
\frac{\sum_{i} \frac{\left(V_{i}-V_{i+1}\right) \cdot\left(t_{i}+t_{i+1}\right)}{2}}{\sum_{i}\left(V_{i}-V_{i+1}\right)}
$$

where $V_{i}$ is the relative volume at time $t_{i}$ during systole. Ts was therefore derived from the sum of the products of successive volume changes and the average time between these frames. Left ventricular ejection time (LVET) was taken to be the time during which $98 \%$ of the total volume change in systole took place. The Ts: LVET ratio thus measures the shape of the volume curve in systole ${ }^{14}$; if a greater proportion of the volume empties in early systole then the ratio will be reduced. Regional myocardial fibre shortening is maximal during early systole and the ratio will thus correlate inversely with the intrinsic contractile state of the heart.

Patients rested for 15 minutes before the start of each study. Ventricular volume curves were constructed over 500 beats at rest and over 300 to 500 beats during supine exercise on a bicycle ergometer. The work rate was adjusted for each patient between 300 and $600 \mathrm{kpm} / \mathrm{min}$ and exercise continued for a further two to three minutes before initiating data accumulation. After a further 30 minute rest period, 
propranolol $0.15 \mathrm{mg} / \mathrm{kg}$ (ICI Pharmaceuticals, UK) was given over five minutes by intravenous injection and the procedure repeated after 15 minutes. Systolic blood pressure was measured by the same observer using a mercury sphygmomanometer at rest and on exercise before and after propranolol. The same procedure at the same work loads was used for each patient at restudy when euthyroid.

Thyroid function tests were undertaken before each study. Plasma total $T_{4}$ was measured by specific radioimmunoassay. ${ }^{15}$ The interassay precision level using anonymous control sera averaged $11.7 \%$ for $\mathrm{T}_{4}$, expressed as the coefficient of variation. The normal range for plasma total $T_{4}$ in our laboratory is 60 to 150 $\mathrm{nmol} / \mathrm{l}$. Plasma thyroid stimulating hormone was also measured by radioimmunoassay ${ }^{16}$ in which the between assay coefficient of variation was $11.2 \%$. The normal range for plasma thyroid stimulating hormone is less than 0.7 to $5.7 \mathrm{mU} / 1$.

Statistical analysis used the Wilcoxon ranked sum and signed rank two-tailed test for pair differences. Correlations between left ventricular ejection fraction, heart rate, and plasma thyroxine used a linear regression coefficient with least squares method of analysis. A $5 \%$ level of confidence was considered statistically significant. All data are quoted as mean \pm standard error of the mean (SEM).

\section{Results}

The resting left ventricular ejection fraction was significantly less when hypothyroid $(0.46 \pm 0.02)$ compared with the same patients when euthyroid $(0.53 \pm 0.02 ; p<0.01)$ (Fig. 1). On exercise, left ventricular ejection fraction increased in the hypothyroid patients to $0.51 \pm 0.02(p<0.05$ compared with resting level). One patient (case 8) showed no change in ejection fraction on exercise and case 2 showed a modest

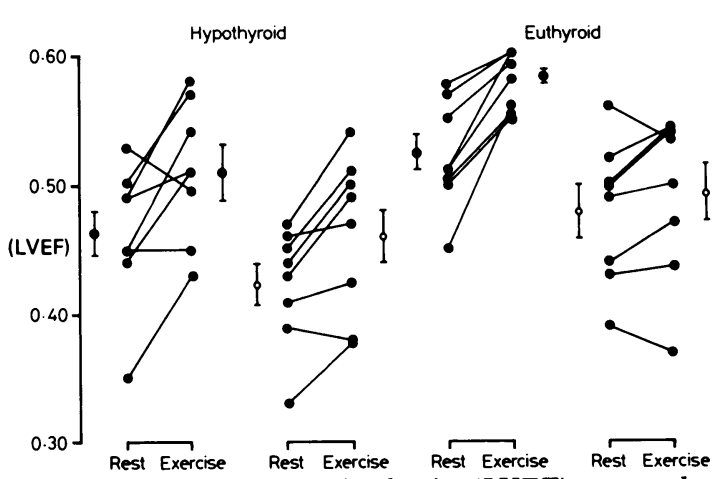

Fig. 1 Left ventricular ejection fraction (LVEF) at rest and on exercise in the hypothyroid and euthyroid groups. The closed symbols are before and the open symbols after propranolol 0.15 mg/kg intravenously. fall from 0.53 to 0.49 . All patients showed an increase in left ventricular ejection fraction on exercise when euthyroid (exercise ejection fraction $0.58 \pm 0.01$; $\mathrm{p}<0.01$ compared with resting levels). The rise in left ventricular ejection fraction with exercise was not significantly different between the two groups.

Resting left ventricular ejection fraction in the hypothyroid patients fell to $0.42 \pm 0.02$ after intravenous propranolol and in the euthyroid patients fell to $0.48 \pm 0.02$ with beta adrenoceptor blockade (Fig. 1). This represents a $9 \%$ fall in ejection fraction with propranolol when hypothyroid and when euthyroid $(p<0.05)$. With exercise, propranolol caused a $10 \%$ fall in left ventricular ejection fraction in the hypothyroid patients and a $15 \%$ fall in the euthyroid patients $(p<0.01$ compared with resting levels before propranolol). Thus, propranolol attenuated the rise in left ventricular ejection fraction with exercise rather more in the euthyroid than in the hypothyroid groups.

The increase in left ventricular ejection fraction with exercise and the decrease with propranolol are summarised in Fig. 2a and 2b. There was a trend for propranolol to cause a greater attenuation of the exercise-induced rise in left ventricular ejection fraction and a greater absolute fall in left ventricular ejection fraction on exercise in the euthyroid compared with hypothyroid groups, but no statistically significant differences were identified.

Changes in Ts: LVET ratio were in close agreement with changes in left ventricular ejection fraction (Fig. 3). When hypothyroid, the ratio reduced from $0.560 \pm 0.016$ at rest to $0.519 \pm 0.022$ on exercise $(\mathrm{p}<0.01)$ in keeping with an increase in left ventricular ejection fraction. After propranolol, the resting Ts:LVET ratio increased to $0.587 \pm 0.016(p=0.10)$ in
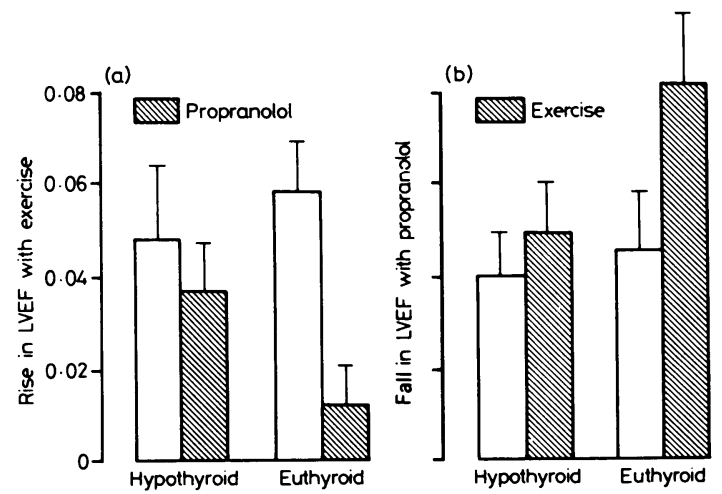

Fig. 2 Changes in left ventricular ejection fraction (LVEF) with exercise and beta adrenoceptor blockade. The rise in $L V E F$ with exercise before and after propranolol is shown in Fig. $2 a$ and the fall in LVEF with propranolol at rest and on exercise is shown in Fig. $2 b$. 
Table 2 Heart rate and blood pressure responses to exercise and beta adrenoceptor blockade in patients when hypothyroid and when euthyroid on thyroxine replacement treatment

\begin{tabular}{|c|c|c|c|c|}
\hline & \multicolumn{2}{|l|}{ Hypothyroid } & \multicolumn{2}{|l|}{ Euthyroid } \\
\hline & $\begin{array}{l}\text { Mean heart } \\
\text { rate (beats/min) }\end{array}$ & $\begin{array}{l}\text { Systolic blood } \\
\text { pressure ( } \mathbf{m m H g} \text { ) }\end{array}$ & $\begin{array}{l}\text { Mean heart } \\
\text { rate (beats/min) }\end{array}$ & $\begin{array}{l}\text { Systolic blood } \\
\text { pressure (mmHg) }\end{array}$ \\
\hline $\begin{array}{l}\text { Rest } \\
\text { Exercise } \\
\text { Rest (propranolol) } \\
\text { Exercise (propranolol) }\end{array}$ & $\begin{array}{l}67 \pm 4 \\
97 \pm 5 \\
59 \pm 4 \\
82 \pm 6\end{array}$ & $\begin{array}{l}135 \pm 6 \\
167 \pm 6 \\
131 \pm 6 \\
151 \pm 8\end{array}$ & $\begin{array}{r}79 \pm 2 \\
106 \pm 4 \\
71 \pm 4 \\
90 \pm 3\end{array}$ & $\begin{array}{l}128 \pm 6 \\
167 \pm 8 \\
123 \pm 5 \\
151 \pm 5\end{array}$ \\
\hline
\end{tabular}

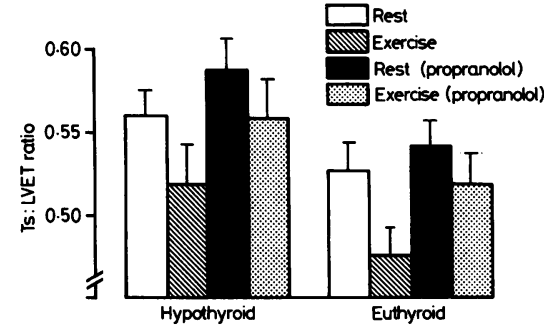

Fig. 3 Ts:LVET ratio (see methods) in hypothyroid and euthyroid groups. $A$ fall in the ratio indicates an increase in myocardial contractile performance.

the hypothyroid group and the fall on exercise was somewhat reduced $(0.548 \pm 0.021)$. In the euthyroid state the ratios were significantly less than when hypothyroid both at rest and on exercise $(p<0.05)$, but a similar reduction was seen on exercise before propranolol (from $0.527 \pm 0.018$ to $0.471 \pm 0.020$; $\mathrm{p}<0.025$ ) with an attenuated fall after propranolol (from $0.542 \pm 0.016$ to $0.517 \pm 0.021 ; p<0.05$ ).

Changes in systolic blood pressure and mean heart rate are detailed in Table 2 . No significant differences in resting or exercise systolic blood pressure were detectable in the two groups either before or after propranolol. Mean heart rate was reduced when hypothyroid at rest $(67 \pm 4$ beats/min against $79 \pm 2$ beats/min euthyroid; $p<0.01)$, and on exercise $(97 \pm 5$ beats/min against 106 \pm 4 beats/min euthyroid; $p<0.05)$. Propranolol caused a $12 \%$ reduction in resting heart rate when hypothyroid and a $10 \%$ reduction when euthyroid. The percentage reduction in exercise heart rate with propranolol was also similar, being $10 \%$ when hypothyroid and $15 \%$ when euthyroid.

There was no correlation between left ventricular ejection fraction or Ts:LVET ratio and thyroid hormone levels in either the hypothyroid or euthyroid state. When hypothyroid, resting heart rate was related to plasma total thyroxine, the correlation coefficient $(r=0.59 ; p<0.05)$ being improved by beta adrenoceptor blockade $(r=0.69 ; p<0.05)$. Heart rate at rest or on exercise was unrelated to plasma total thyroxine when euthyroid.

No abnormalities in regional wall motion were detected in any patient at rest or on exercise before or after propranolol.

\section{Discussion}

Although the mode of action of thyroid hormones has not been fully elucidated, much evidence favours binding to nuclear chromatin as the principal site of action, with secondary modulation of protein synthetic pathways. ${ }^{17}$ It is therefore not surprising that alterations in many aspects of cellular function have been reported in thyroid hormone deficiency as well as thyroid hormone excess. ${ }^{18} \mathrm{~A}$ nuclear binding site does not, however, exclude effects on the plasma membrane or mitochondrial membrane in initiating thyroid hormone action. A reduction in beta adrenoceptor density in ventricular membranes from hypothyroid rats ${ }^{11}$ suggests that a change in the number of catecholamine receptor sites, leading to adrenergic hyposensitivity, might be an important effect of hypothyroidism. It is far from clear, however, whether altered beta adrenoceptor density in vitro would cause a change in sympathetic sensitivity in vivo in view of the close relation between the presynaptic nerve terminal and postsynaptic myocardial cells in the regulation of inotropic and chronotropic responses to neurotransmitter release.

This study has therefore investigated myocardial contractile function in hypothyroid and euthyroid patients at rest and on exercise before and after beta adrenoceptor blockade. By using the same patients as controls, the problems of inter-individual variability are avoided. The findings suggest that there are no significant differences in left ventricular contractile responses to increased sympathetic tone (exercise) or to sympathetic blockade (propranolol) in the hypothyroid and euthyroid state. There is, however, an absolute reduction in myocardial contractile performance at rest and on exercise in hypothyroidism that is independent of beta adrenoceptor activation and is presumably a direct effect of thyroid hormone deficiency. The changes in contractile function at rest and on exercise when euthyroid are within the normal range of response in our laboratory.

Heart rate itself may be a determinant of contractile 
performance in man. ${ }^{19}$ The fall in left ventricular ejection fraction in hypothyroidism might thus be partly caused by the reduction in heart rate at rest and on exercise (Table 2). We have, however, shown that increase in heart rate after vagal blockade with atropine has no effect on left ventricular ejection fraction or Ts:LVET ratio. ${ }^{14}$ Furthermore, Wainwright et al. ${ }^{20}$ showed that with incremental right ventricular pacing up to 125 beats/min, left ventricular ejection fraction progressively decreases. In the present study, exercise left ventricular ejection fraction when hypothyroid was still slightly less than resting left ventricular ejection fraction when euthyroid despite a substantially higher heart rate in the former group. It is likely therefore that there is a true reduction in myocardial contractile performance at rest and on exercise in hypothyroidism.

Both clinical ${ }^{21}$ and necropsy ${ }^{22}$ studies have shown that coronary artery disease occurs more frequently in hypothyroid patients than in controls matched for age, sex, blood pressure, and associated extrathyroid disorders. This agrees with experimental data to show that thyroid hormone deficiency potentiates the development of atherosclerosis in cholesterol-fed animals and that thyroid hormone administration can inhibit atherogenesis. ${ }^{23}$ The incidence of coronary disease in our series is unknown but it is of interest that the patient in whom a clinical diagnosis of angina pectoris was made was the only patient to show a small fall in left ventricular ejection fraction on exercise in the hypothyroid state. A fall in left ventricular contractile performance on exercise is readily demonstrable in patients with coronary disease ${ }^{24}$ and this is the probable explanation in this patient. Intriguingly, left ventricular ejection fraction increased normally in this patient when euthyroid. Histological study of the myocardium in cases of severe hypothyroidism shows non-specific changes of myofibrillar swelling, oedema, and interstitial fibrosis. ${ }^{25}$ It is possible that irreversible impairment of cardiac function may develop in such extreme cases, though all of our patients showed a return to normal function a maximum of eight months after starting oral thyroxine.

Previous studies into the effect of propranolol on resting left ventricular ejection fraction in normal subjects have given conflicting results, with either no effect or a depressant effect on resting ventricular performance. ${ }^{24}$ 26-29 Differences are probably related to variability in drug dosage and route of administration, subject selection, and methods of assessment of contractile performance. On exercise ventricular performance is consistently depressed ${ }^{29}$ independent of its effect on heart rate. ${ }^{30} 31$ Our studies have shown that propranolol does not modify the pattern of change in contractile performance at rest or on exercise in the hypothyroid state. Attenuation of the exercise- induced rise in contractility was similar to that when euthyroid.

Although absorption of propranolol ${ }^{32}$ and other drugs ${ }^{3334}$ is impaired in hypothyroidism, propranolol metabolism ${ }^{32}$ and plasma protein binding ${ }^{35}$ are not influenced by thyroid status. It is thus unlikely that there would be major differences in plasma propranolol concentrations after intravenous administration when hypothyroid or euthyroid. A reduction in peak exercise tachycardia of $16 \%$ when hypothyroid and $15 \%$ when euthyroid suggests similar functional beta adrenoceptor antagonism in both groups. The dose of propranolol used $(0.15 \mathrm{mg} / \mathrm{kg})$ has been shown to cause a 20 to 30 fold increase in the isoprenaline dose required to increase heart rate by 25 beats/min and to give plasma propranolol concentrations in the range 50 to $100 \mathrm{ng} / \mathrm{ml},{ }^{36}$ suggesting satisfactory beta adrenoceptor blockade over the study periods.

Propranolol administration causes a fall in levels of circulating tri-iodothyronine, physiologically the most important thyroid hormone, and a rise in levels of the metabolically inactive isomer "reverse" triiodothyronine ${ }^{37}$ The drug probably acts similarly to non-thyroidal illness, either by alternative peripheral monodeiodination of thyroxine ${ }^{38}$ or by reduction in activity of the deiodinase enzyme activity responsible for tri-iodothyronine production. ${ }^{39}$ Though this may have important consequences in hyperthyroidism, ${ }^{40}$ it is unlikely to contribute to the acute effects of propranolol in hypothyroidism.

Left ventricular function is reversibly depressed by thyroid hormone deficiency but responses to exercise before and during beta adrenoceptor blockade are normal. We have not shown any evidence of altered adrenergic sensitivity in the control of myocardial contractile function in hypothyroidism. This suggests that myocardial depression in thyroid failure is independent of the cardiac neurosympathetic axis. Changes in adrenoceptor density in this condition, if they occur in man, appear not to be associated with a change in functional response of the heart to altered sympathetic tone.

\section{References}

1 Buccino RA, Spann JF Jr, Sonnenblick EH, Braunwald E. Influence of thyroid state on the intrinsic contractile properties of the myocardium (abstract). Circulation 1966; 34, suppl III: 67-8.

2 Strauer BE, Schulze W. Experimental hypothyroidism: depression of myocardial contractile function and hemodynamics and their reversibility by substitution with thyroid hormones. Basic Res Cardiol 1976; 71: $624-44$.

3 Taylor RR, Covell JW, Ross J Jr. Influence of the thyroid state on left ventricular tension-velocity relations 
in the intact, sedated dog. $f$ Clin Invest 1969; 48: 775-84.

4 Crowley WF Jr, Ridgway EC, Bough EW, et al. Noninvasive evaluation of cardiac function in hypothyroidism: response to gradual thyroxine replacement. $N$ Engl $\mathcal{F}$ Med 1977; 296: 1-6.

5 Burckhardt D, Staub JJ, Kraenzlin M, Raeder E, Engel $\mathrm{U}$, Cloppenburg $\mathrm{P}$. The systolic time intervals in thyroid dysfunction. Am Heart $\mathcal{f}$ 1978; 95: 187-96.

6 Chakravarty J, Guansing AR, Chakravarty S, Hughes CV. Systolic time intervals (STI) as indicators of myocardial thyroid hormone effect: a correlative study in hypothyroid and hyperthyroid patients. Acta Endocrinol (Kbh) 1978; 87: 507-15:

7 Amidi M, Leon DF, DeGroot WJ, Kroetz FW, Leonard JJ. Effect of the thyroid state on myocardial contractility and ventricular ejection rate in man. Circulation 1968; 38: 229-39.

8 Cohen MV, Schulman IC, Spenillo A, Surks MI. Effects of thyroid hormone on left ventricular function in patients treated for thyrotoxicosis. Am J Cardiol 1981; 48: 33-8.

9 Benforado JM, Wiggins LL. Contractility, heart rate, and response to norepinephrine of isolated rat myocardium following $1^{131}$ induced hypothyroidism. I Pharmacol Exp Ther 1965; 147: 70-5.

10 Margolius HS, Gaffney TE. The effects of injected norepinephrine and sympathetic nerve stimulation in hypothyroid and hyperthyroid dogs. $\mathcal{F}$ Pharmacol Exp Ther 1965; 149: 329-35.

11 Ciaraldi T, Marinetti GV. Thyroxine and propylthiouracil effects of vivo on alpha and beta adrenergic receptors in rat heart. Biochem Biophys Res Commun 1977; 74: 984-91.

12 Millar AM, Hannan WJ, Sapru RP, Muir AL. An evaluation of six kits of technetium $99 \mathrm{~m}$ human serum albumin injection for cardiac blood pool imaging. Eur $\mathcal{f} \mathrm{Nucl}$ Med 1979; 4: 91-4.

13 Muir AL, Hannan WJ, Brash HM, Baldwa V, Miller HC, Ogilvie B. The assessment of left ventricular ejection fraction in patients with ischaemic heart disease by contrast ventriculography and nuclear angiography. Clin Sci Mol Med 1977; 53: 55-61.

14 Muir AL, Hannan WJ, Sapru RP, Boardman AK, Wraith PK, Brash HM. The effects of isoprenaline, atropine and dobutamine on ventricular volume curves obtained by radionuclide ventriculography. Clin Sci 1980; 58: 357-64.

15 Seth J, Toft AD, Irvine WJ. Simple solid phase radioimmunoassays for total triiodothyronine and thyroxine in serum and their clinical evaluation. Clin Chim Acta 1976; 68: 291-301.

16 Irvine WJ, Toft AD, Hunter WM, Kirkham KE. An assessment of plasma TSH radioimmunoassay and of the TSH stimulation test in the diagnosis of 100 consecutive patients with suspected hypothyroidism. Clin Endocrinol 1973; 2: 135-9.

17 Tata JR, Ernster L, Lindberg O, Arrhenius E, Pedersen $S$, Hedman $R$. The action of thyroid hormones at the cell level. Biochem f 1963; 86: 408-28.

18 Sterling K. Thyroid hormone action at the cell level. $N$ Engl f Med 1979; 300: 173-7.

19 Port S, Cobb FR, Jones RH. Effects of propranolol on left ventricular function in normal men. Circulation 1980; 61: 358-66.

20 Wainwright RJ, Brennand-Roper D, Shenasa M, Maisey $M N$, Sowton E. Evaluation of rate programmable permanent pacemakers using technetium-99m gated cardiac blood pool scintigraphy (99 $\mathrm{Tc}^{\mathrm{m}} \mathrm{GBPS}$ ) (abstract). $\mathrm{Br}$ Hean f 1980; 43: 115-6.

21 Vanhaelst L, Neve P, Chailly P, Bastenie PA. Coronary-artery disease in hypothyroidism. Lancet 1967; ii: $800-2$.

22 Steinberg AD. Myxedema and coronary artery disease-a comparative autopsy study. Ann Intern Med 1968; 68: 338-44.

23 Myasnikov AL, Myasnikov LA, Zaitzev VF. The influence of thyroid hormones on cholesterol metabolism in experimental atherosclerosis in rabbits. $\mathcal{f}$ Atheroscler Res 1963; 3: 295-300.

24 Marshall RC, Wisenberg G, Schelbert HR, Henze E. Effect of oral propranolol on rest, exercise and postexercise left ventricular performance in normal subjects and patients with coronary artery disease. Circulation 1981; 63: 572-83.

25 Douglass RC, Jacobson SD. Pathologic changes in adult myxedema-survey of 10 necropsies. $f$ Clin Endocrinol Metab 1957; 17: $1354-64$.

26 Shubrooks SJ Jr, Zir LM, Dinsmore RE, Harthorne JW. Left ventricular wall motion response to intravenous propranolol. Circulation 1975; 52: 124-9.

27 Helfant RH, Herman MV, Gorlin R. Abnormalities of left ventricular contraction induced by beta-adrenergic blockade. Circulation 1971; 43: 641-7.

28 Frishman W, Smithen C, Befler B, Kligfield P, Killip T. Non-invasive assessment of clinical response to oral propranolol therapy. Am $\mathcal{F}$ Cardiol 1975; 35: 635- 44.

29 Baron DW, Clements IP, Becker GP, Harrison CE, Brown ML. Radionuclide ventricular volumes during supine and upright exercise in normal men before and after propranolol (abstract). Circulation 1980; 62, suppl III: 102.

30 Ehrhardt JC, Verani MS, Marcus ML. Exercise isotope ventriculogram: use in assessing changes in left ventricular function (abstract). Circulation 1977; 56, suppl III: 141.

31 Sonnenblick EH, Braunwald E, Williams JF Jr, Glick G. Effect of exercise on myocardial force-velocity relations in intact unanesthetized man: relative roles of changes in heart rate, sympathetic activity and ventricular dimensions. $f$ Clin Invest 1965; 44: 2051-62.

32 Bell JM, Russell CJ, Nelson JK, Kelly JG, McDevit DG. Studies of the effect of thyroid dysfunction on the elimination of beta-adrenoceptor blocking drugs. $\mathrm{Br} \mathcal{F}$ Clin Pharmacol 1977; 4: 79-82.

33 Forfar JC, Pottage A, Toft AD, Irvine WJ, Clements JA, Prescott LF. Paracetamol pharmacokinetics in thyroid disease. Eur $\mathcal{F}$ Clin Pharmacol 1980; 18: 269-73.

34 Croxson MS, Ibbertson HK. Serum digoxin in patients with thyroid disease. $\mathrm{Br}$ Med $\mathcal{F}$ 1975; iii: 566-68.

35 Kelly JG, McDevitt DG. Plasma protein binding of propranolol and isoprenaline in hyperthyroidism and hypothyroidism. Br f Clin Pharmacol 1978; 6: 123-7.

36 Coltart DJ, Shand DG. Plasma propranolol levels in the quantitative assessment of beta-adrenergic blockade in 
man. $B r$ Med f 1970; iii: 731-4.

37 Harrower ADB, Fyffe JA, Horn DB, Strong JA. Thyroxine and triiodothyronine levels in hyperthyroid patients during treatment with propranolol. Clin Endocrinol 1977; 7: 41-4.

38 Burger A, Nicod P, Suter P, Vallotton MB, Vagenakis A, Braverman L. Reduced active thyroid hormone levels in acute illness. Lancet 1976; i: 653-5.

39 Kaplan MM, Utiger RD. Iodothyronine metabolism in rat liver homogenates. $\mathcal{f}$ Clin Invest 1978; 61: 459-71.

40 Forfar JC, Miller HC, Toft AD. Occult thyrotoxicosis: a correctable cause of "idiopathic" atrial fibrillation. Am $\mathcal{f}$ Cardiol 1979; 44: 9-12.

Requests for reprints to Dr J C Forfar, Department of Cardiology, Royal Infirmary, Edinburgh EH3 9YW. 